The Geneva Papers on Risk and Insurance, 23 (No. 86, January 1998), 112-122

\title{
Risks in Teleworking on the Information Highway*
}

\author{
by Simon Robinson**
}

\section{Introduction}

Teleworking in the general sense is the use of information and communication technologies to perform and manage work taking place at distributed sites. No attempt is made in the paper to cover evenly this very broad field, instead, examples of some topical interest are chosen for discussion at the seminar, drawn from projects in progress at empirica:

- teleworking in the now traditional sense of using telematics to enable work from (near) home,

- the use of information highways to help manage business processes and support electronic commerce, and

- ways in which information highways are now being utilised to help elderly people live independently.

\section{2. “Traditional” Teleworking}

The particular interest teleworking generates in the media is the ability of telework to reduce commuting, to move work to people rather than moving people to work every day. Many other advantages can be drawn from telework, including the ability to revitalise remote regions or to enable people to deal more effectively with both family and work commitments.

\footnotetext{
* Paper presented at the 12th MORE Seminar of the Association Internationale pour l'Etude de l'Economie de l'Assurance, Winterthur, 1997.

** Empirica Gesellschaft für Kommunikations- und Technologieforschung mbH, Oxfordstraße 2, D-53111 Bonn.
} 
Growing attention has been paid to these opportunities by political and organisational decision-makers since "telecommuting" first became a topic for research during the oil crisis of the 1970s. Only recently however are there signs that environmental, attitudinal, political, technological and organisational conditions are such that the move away from traditional ways of working that telework represents can take place and is taking place to a quantitatively significant extent.

One of the difficulties faced by managers and politicians alike in understanding the opportunities telework offers and how they could be taken up had been the lack of reliable data about this form of work. Some improvement came with the last pan-European survey carried out by empirica in 1994 (Robinson \& Kordey 1994; Korte \& Wynne 1996). This enabled the first relatively reliable estimates to be made of the levels of teleworking practised at the time.

The figures on teleworking practice refer to "traditional" forms of teleworking. As noted above, teleworking in the general characterised by a increase in freedom to relocate work. Using information and communications technologies, work can be relocated at minimal cost, so that the location chosen for work can be determined by the needs of the teleworkers themselves, e.g. working at or near home, and/or the needs of the employing organisation, e.g. placing satellite offices in low-rent suburbs or industrial zones. For the purposes of a survey this general definition has to be made sufficiently precise for respondents to grasp quickly. Correspondingly, the 1994 survey dealt with working at home, in neighbourhood or satellite offices. Also, to maintain a focus on new, comparatively radical changes in working patterns, the survey of telework also excluded the practice of using laptop computing to take work home of an evening, by stipulating that at least one full day's work takes place at a site remote from a central office (Robinson / Kordey 1994).

Based on the four large countries surveyed, results showed that in 1994, telework had already reached over 1 million people in Europe. However, the distribution was markedly uneven, with the UK providing roughly half the teleworkers in the sample (Figure 1), and Germany despite its size and the sophistication of its telecommunications infrastructure in low mid-field.

There are several possible reasons why Germany has been lagging in telework practice, not least of which has been the legacy of a strongly critical attitude adopted by labour representatives in the 1980s. Watchful of any threat to organisation of labour interests and fearful for their members of a move to a new unregulated "Heimarbeit", German trade union leaders were regularly publicly critical of this kind of workplace innovation. Since the early 90s, this tide has been turning (e.g. Welsch 1991), and while remaining wary of the risks, trade unions in Germany now work constructively on working out appropriate agreements for the various issues of interest involved.

This change in stance by labour leaders has been mirrored in or reflects a sea change in attitudes in the workforce, revealed by comparing data from 1994 with that from a similar survey carried out in 1985 (Huws, Korte \& Robinson 1990). As the table shows, though less than $9 \%$ of Germans were willing to work from home in 1985, attitudes have changed dramatically in the past decade. Levels of interest current in 1994 brought Germany into line with other European countries, whose populations have also been 
Figure 2.1: Numbers practising telework 1994

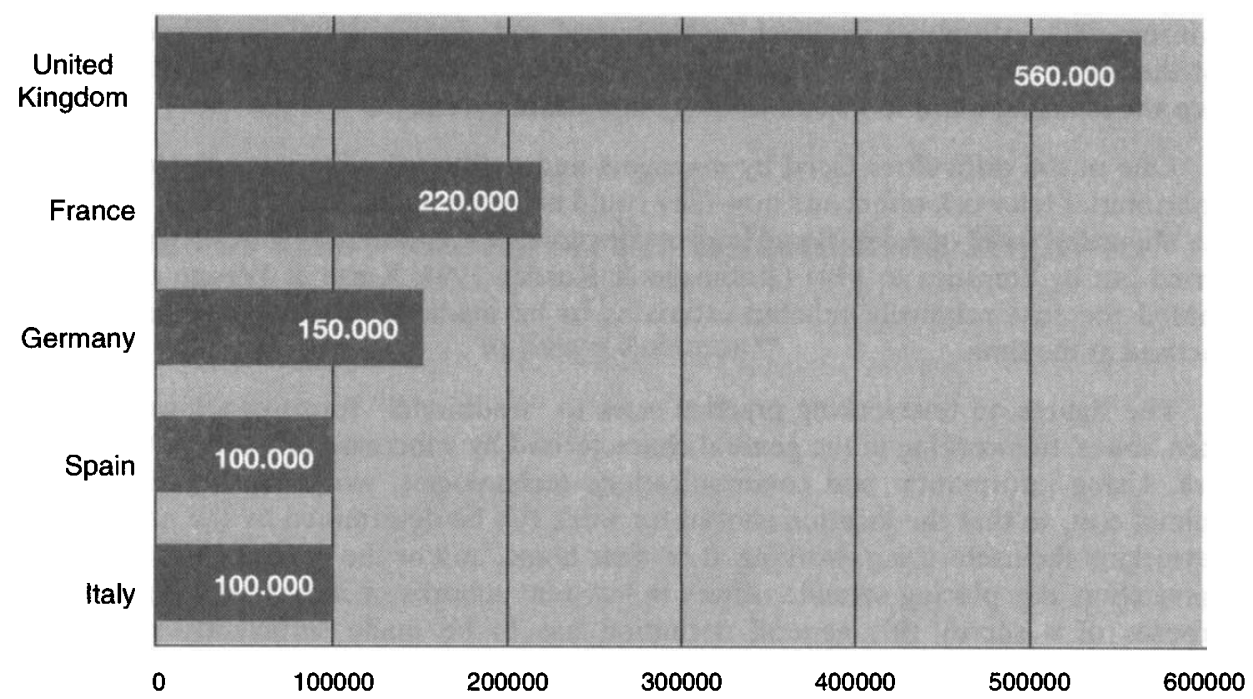

Figure 2.2: Interest in Telework (Telehomework)

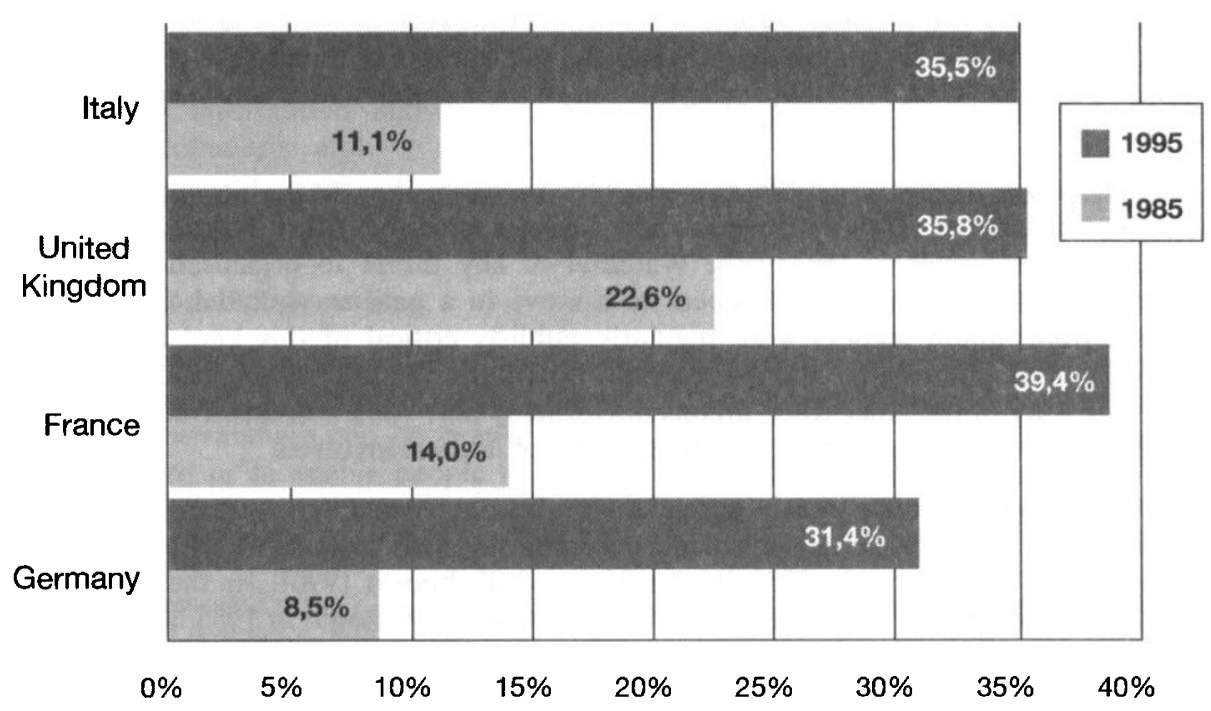


changing their view of telework but who in most cases set out from a less fundamentally critical position.

Telework is now being taken up across the board by businesses and public bodies in Germany. In the insurance sector, those most active recently have included the Continentale Versicherung in Dortumund, the Württembergische in Stuttgart, LVM Münster (Bauer 1997, Schmidt 1997). As is particularly appropriate in an industry dealing in risks, insurance companies such as the Continentale and Württemburgische are approaching the introduction of telework with care, setting clearly-defined organisational goals to be reached. For the Continentale, these goals include improving productivity by taking advantage of reduced interruptions, enabling service hours to be extended into evenings and week-ends, cutting the cost of central office rent and enabling qualified staff who have to move away with their families or who have responsibilities for small children to continue to contribute. To avoid the down-side of isolation, most teleworking schemes provide for regular periods of work at the central office.

Risks in teleworking from home include a number of obvious items such as the exposure of (company) equipment to loss or damage in a home office. Without proper organisation and communications infrastructure, employees risk suffering isolation from colleagues, or career disadvantages. Also, being presented with production targets without monitored working time potentially leads to threats to health through overlong periods of work. From the point of view of the organisation, there may be a greater exposure to loss from equipment down-times. Though work in conventional settings already requires the proper functioning of host computers and local area networks, teleworking can increase the reliance on public telecommunications networks and services in particular. Security issues must also be addressed properly, and in many businesses it is particularly important to ensure that customer data is not exposed to those possible breaches in security which become more likely in teleworking settings.

Where the opportunities telework provides are extensively used, organisations change in character in a way possibly introducing new levels of risk. Rauser Advertainment is a company set up from Stuttgart to produce a particular kind of information product - advertising in computer games. The production teams take full advantage of global networks, e.g. in one case choosing to work from a Florida beach rather than in Gelsenkirchen for most of the year (Rauser 1997). "Virtual" organisations such as this recruit personnel via the Internet market place rather than the conventional job application and interview process, and the employee may not see the person concerned through the entire process of agreeing on work to be done. As Rauser reports, this can lead to an increase in breaches of trust. In comparison with traditional, exclusive employment, it is difficult for the company to command loyalty from a workforce of shifting composition and with multiple clients. For companies run in this way, it can be a problem that free-lance professionals and other workers tend to view the results of their labour as their own, and may feel free to sell ideas on to competitors, as the opportunity arises. In contrast, the exclusive and generally longer-term employment characteristic of conventional organisations enables quite simple security and managerial control systems to be effective, so that the organisation can build and protect a knowledge base on which to establish a competitive position. 
Figure 2.3: Telework and the "Virtual" Organisation - an example

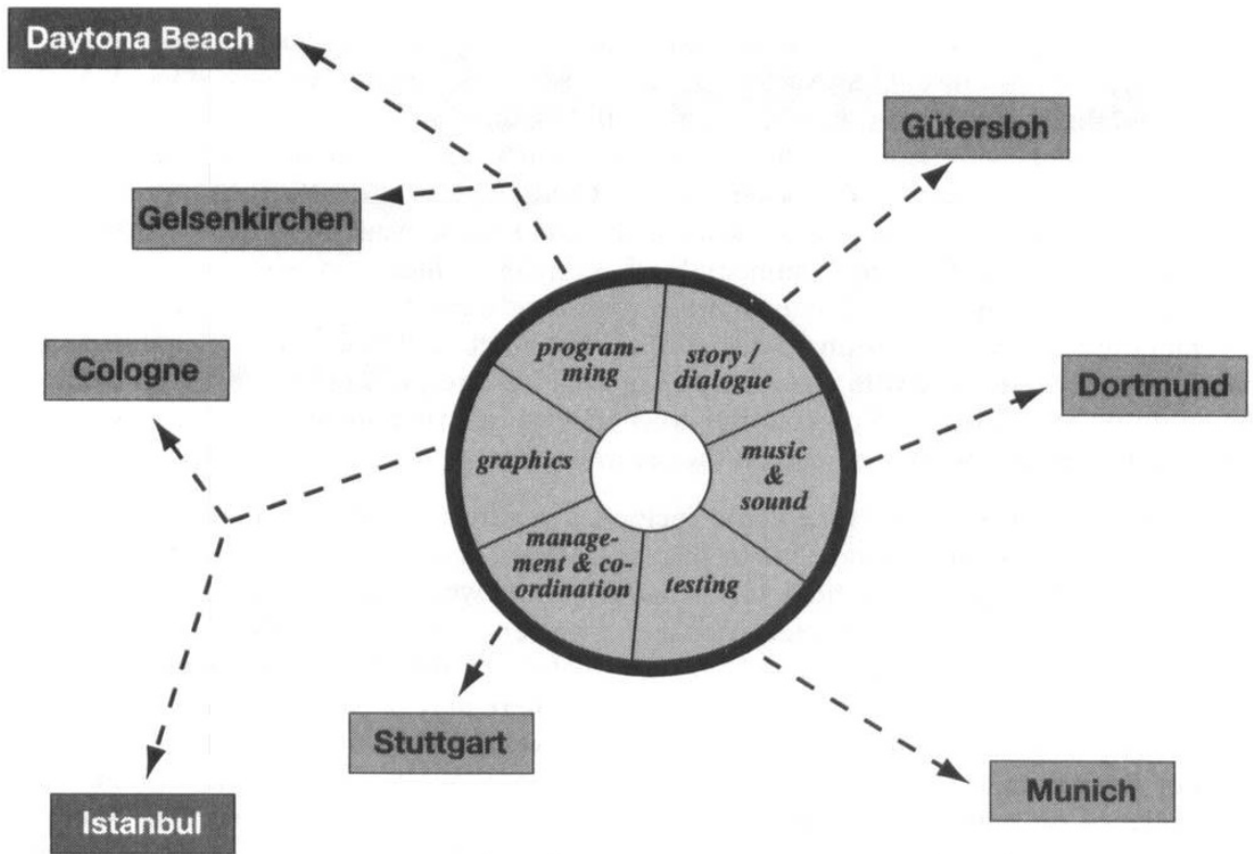

Here as in telework generally, there is a need for an appropriate legal framework and model contractual agreements for a proper and appropriate distribution of the risks involved in teleworking.

The current legal framework for most employment in Europe is built around a traditional view of the organisation of work: the model of full-time employment with a single employer taking place on company premises. Risks associated with employment for those within the model have been successively reduced, with the topical side-effect of increasing the cost to the employer of this type of working relationship. Those falling outside the model suffer from significantly higher and in some cases unacceptable levels of risk. As teleworking and other kinds of part-time and non-exclusive working from a variety of premises and from on the move spread, so the systems of protection introduced for employees applies to fewer in the workforce. The pressure from unions to maintain the traditional employment model is not limited to Europe, as the recent UPS strike in the US demonstrated.

The distribution of risk can be regulated at a number of levels. At the level of widest applicability, national and supra-national labour law covers areas ranging from protection from dismissal to ensuring non-discrimination in job-seeking. Proposals for legislating on telework-specific issues, a "telework law", have not met with any success to date. The next level of generality is the collective agreement between employers and unions across a 


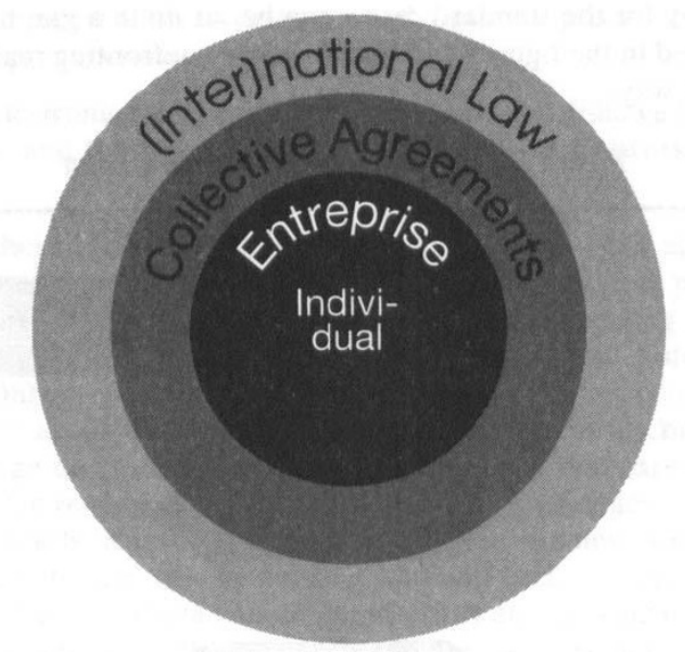

particular industry or sector. This has historically been of great importance in Germany. However, in the latter country as elsewhere, the diversification of markets and activities has led to wide variation in profitability within formerly homogenous sectors, leading to pressure to move bargaining to smaller units, down to the enterprise or plant level. This is also a level at which agreements on potentially controversial issues can be reached relatively easily, and where therefore innovation is possible. Finally, individual agreements with those working for an organisation may be tailored to their specific circumstances. As an appropriate compromise between generality of application and specificity to differing circumstances, enterprise and plant-level agreements are currently the main vehicle for innovation in telework risk-sharing agreements (e.g. IBM Germany, cf. Robinson \& Huws 1993).

\section{Business processes and electronic commerce}

Supporting business processes using workflow management is a fairly recent development in information systems. Workflow provides the kind of automation to office work which has long been common in production. Jobs to be done are moved instantly from desk to desk, replacing the trolley-loads of files dusty from lying in in-trays and outtrays which are still pushed up and down most office buildings.

Workflow management systems separate the idea of process and the design of a process from the resources and people who contribute to carrying it out. A process design is like an assembly line tooled up to produce a particular model of car, but the processes in offices produce instead a solution to a customer's problem, a quote, a decision on planning permission and other, perhaps less tangible but nonetheless valuable results. In the modern office, multiple such "assembly lines" ready to produce a range of services can be 
set up to be continually ready to run on a network of computers. Redesign of a process to make sure the result is better checked before it reaches the customer, or to streamline and speed up delivery for the standard case - can be set up in a graphic representation of the process (illustrated in the figure) and tested before confronting real staff with the need to do the work a new way.

Figure 3.1: Excerpt from a Process Design

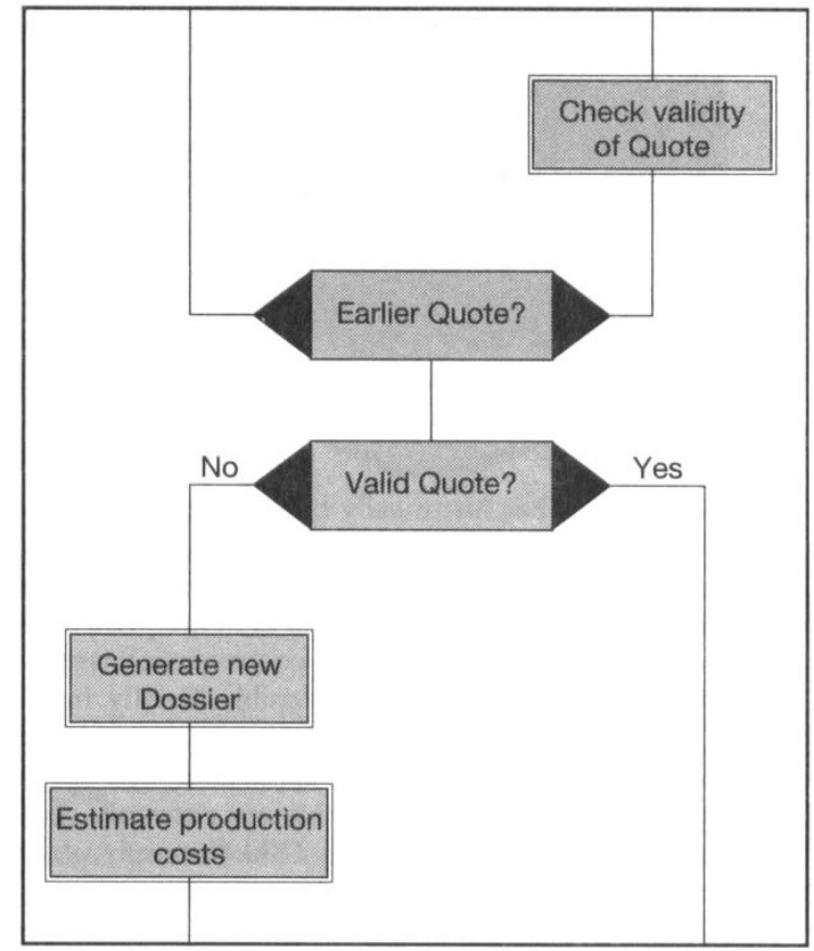

The processes supported by workflow management need not stay in a single office building. In transcending the boundaries of an organisation, workflow management is now becoming part of the booming area of electronic commerce.

Electronic commerce is often understood as simply making payments in a new way. However, electronic cash and online payment are not the only area of electronic commerce, which is usefully seen as covering all uses of telecommunications networks and services to carry out commercially relevant transactions and agreements of any kind. Workflow management becomes electronic commerce as the processes supported extend to include action and events beyond the bounds of the individual company. That which has been seen traditionally as "other people's work" is "included" in the process. Work that customers perform, e.g. in filling out forms or pressing buttons in a cash dispenser, becomes part of the process design, requiring new techniques to take due account of the 
fact that the customer is not a member of staff of the organisation and cannot be treated as if he or she had a contract or were being paid a salary. Nevertheless, treating customer work as part of the process leads to designs which optimise process effectiveness from the point of view of the process owner.

In extended electronic commerce, processes are also followed back up the supply chain to suppliers - and through traditional office walls to teleworkers at home or on a business trip.

For users of these technologies, PEST-analysis reveals risks at the political level lack of standards means that systems used to design and support processes in different companies in a supply chain may well be incompatible, leading to costly and timeconsuming work on patching systems together. Moving to these systems is as yet a largescale investment. Only recently has the cost of software begun to fall, and only now are techniques becoming available for the analysis and redesign of the business process which do not consume large quantities of expensive consultancy and expert time. At the same time the benefits often remain difficult to predict with any accuracy - a significant problem given the still high levels of investment. At social level, the new ways of working may, if care is not taken, lead to rejection by existing staff and their resistance to its introduction. Among the technical issues which can consume effort and in which risk is involved is the choice of an appropriate level of security. If too few security measures are adopted the likelihood of customer information being lost to outsiders or manipulation and fraud taking place becomes unacceptably high. However, if security is taken too seriously, this can be a threat to competitiveness as process performance suffers.

Despite the risks involved in its introduction, the risks to competitiveness of not taking up these new technologies are becoming the more significant. Not introducing workflow management means losing transparency, slow processing, tardy response to queries, continuing to require all staff to be present at the same time, inability to change services and products rapidly enough, and can risk loss of an established position in the marketplace.

\section{Care services}

Against the background of an ageing society - the EC population of elderly people will approach 50 million in 2000 - and the trend to single households, Europe in particular is facing a growing problem of caring for its older citizens. Many forms of care require that staff understand the needs of those in their care on a daily or more frequent basis. The telephone is a poor medium for rapidly finding out how someone is and what support they may need, particularly if those concerned are hard of hearing or have some degree of disorientation. Because this kind of service provided in the field is too expensive, many of our elderly citizens are being forced to move out of their homes into appropriately supervised premises.

The recently affordable ability to use information highways to provide "face to face" communication at a distance promises new opportunities to meet these needs.

In 1988, first trials were held in Frankfurt am Main of videotelephony for elderly people. Despite their reputation of being among the least able in the population to learn to 
Figure 4.1: Haus-Tele-Dienst: "face to face" on the information highway
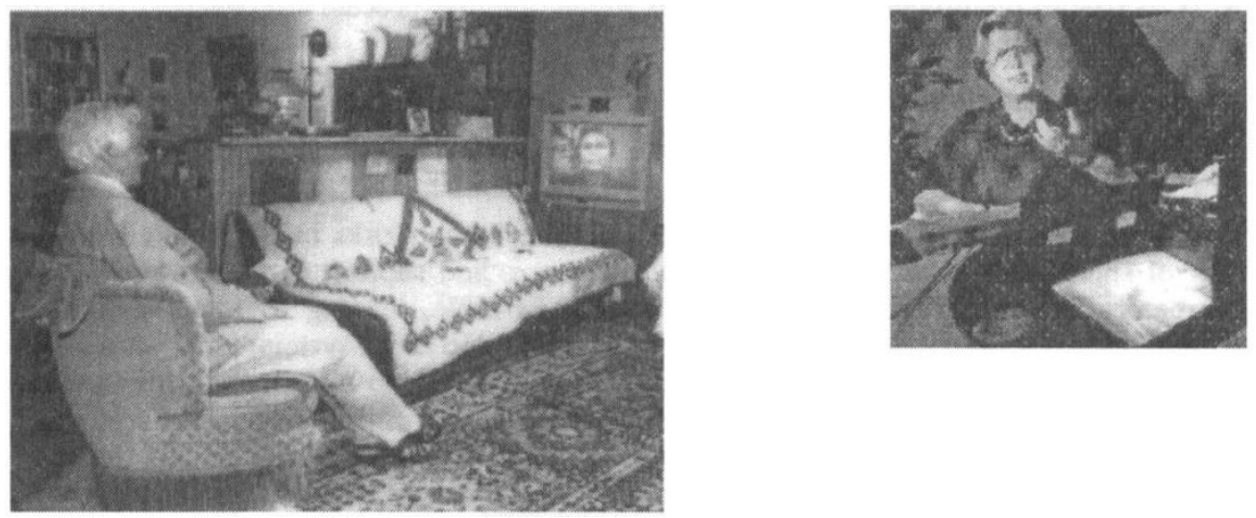

use new technology and among the least interested, quite elderly people were found to find this particular innovation both usable and attractive. It should be said that most had to experience using the technology before they accepted it this way, and that significant effort had been put in making the remote control interface as simple as possible.

As a result of the successful tests, a care service was designed and in 1992 set up for 15 elderly residents of Westhausen in Frankfurt. Here there were more obstacles to be faced in the attitudes of professional social workers used to traditional ways of working. The service provides human mediated information and assistance online, as well as more pro-active support for those in need of this. Apart from the ability to provide a first line of support to elderly people living alone, some support can also be offered to people coping on their own with difficult cases of care for elderly people. Whereas for many care situations, the ability to "look in" to see if the patient is all right has been found very helpful, for other patients, combination with other means of detecting a change in medical condition is indicated. Over four years of the service, calls to the centre have averaged over 200 per month. The service is still available, but cannot be extended using the original analogue techniques. Manufacturers and telecommunications providers have now begun to take an interest in the market, and the service is both being reimplemented using ISDN, ubiquitous in Germany, and parallel work done on providing higher quality videotelephony over cables using digital techniques and on integrating medical systems.

For the purposes of the current seminar, some risks can be identified when care is moved onto information highways. For instance, service providers may be made liable for loss of service or inadequate response in situations which are potentially life-threatening. This loss or inadequacy might be due to network or equipment failure not in the hands of the provider of the service as such. If the security of the system were breached, the information could be used to plan a break-in or other crime. If other, confidential information about a patient gets into the wrong hands, the patients or their relatives may hold the provider liable. There are more complex and sensitive areas of law involved. For 
instance, someone responsible for caring for an elderly patient may be seen as being in breach of their duty by leaving that person in the care of remote staff.

The "Haus-Tele-Dienst" style of care system using videotelephony is only one of a whole range of applications of telematics and information highways now emerging to meet the needs of elderly and disabled people. Related applications of these systems are currently under development, for use in settings as diverse as providing remote interpreters for communication with migrant families, to enabling investment or insurance advice to be given at a distance. Technical developments are also underway, e.g. in the EC projects IBCoBN or ATTRACT, to provide high quality services to more users in an equally affordable way. These and other applications were recently surveyed in the EC project MART (Cullen \& Robinson 1997).

\section{Conclusion}

Each area of teleworking is associated with its own specific types of risk. However, apart from the increased dependency on the functioning of public networks, many of the risks are not essentially new ones. By careful planning and making use of the opportunities information systems provide, these can be minimised. In addition, agreements can be made such that those in a position to limit the risk, participate in its impact.

In as much as introducing telework focusses attention on potential risks, measures may be introduced which reduce the level of risk taken for traditional means of working as well.

Thus all in all, the level of risk depends strongly on the effectiveness of measures taken to minimise each source of risk. The net effect of introducing telework may even be negative: less risk through teleworking on the information highway than in continuing to work the conventional way. 


\section{BIBLIOGRAPHY}

CULLEN, K. \& ROBINSON, S; Telecommunications for Older People and Disabled People in Europe: Preparing for the Information Society; IOS: Amsterdam 1997.

BAUER, R. : Die Einführungsprozeß der Telearbeit in einem Versicherungsunternehmen - Das Beispiel "Die Continentale"; empirica 1997.

EMPIRICA (ed.) Telearbeit Deutschland '96: Neue Formen und Wege zu Arbeit und Beschäftigung. Hüthig: Heidelberg, 1997.

KORTE, W. B, WYNNE, R; Telework. Penetration, Potential and Practice in Europe. IOS Press: Amsterdam 1996

HUWS, U., KORTE, W.B. and ROBINSON, S.; Telework, Towards the Elusive Office. Wiley: London, 1990.

RAUSER, T.; Mit Modem, Mailbox und E-Mail - der grenzenlose Arbeitsmarkt.; empirica 1997.

ROBINSON, S. and HUWS, U.; Technology Requirements Related to the Management of Telework. An Exploratory Investigation for Contractual Arrangements for Telework Employment and Implications for Technology and Service Development. For The Commission of the European Communities Directorate General XIII. Bonn 1993.

ROBINSON, S. \& KORDEY, N.; Teleworking: International Trends. Telekom Anwenderkongress '94, Bonn 1994.

SCHMIDT, W.; Außerbetriebliche Arbeitsplätze für Sachbearbeiter und Führungskräfte bei den LVM Versicherungen.; empirica 1997.

WELSCH, J.; Telearbeit - dort arbeiten, wo man leben möchte? Der Personalrat 12/91, pp 459-462. 